\title{
Sensitivity of water stress in a two-layered sandy grassland soil to variations in groundwater depth and soil hydraulic parameters
}

\author{
M. Rezaei ${ }^{1,2}$, P. Seuntjens ${ }^{1,2,3}$, I. Joris ${ }^{2}$, W. Boënne ${ }^{2}$, S. Van Hoey ${ }^{4}$, P. Campling ${ }^{2}$, and W. M. Cornelis ${ }^{1}$ \\ ${ }^{1}$ Department of Soil Management, Ghent University, Coupure Links 653, 9000 Ghent, Belgium \\ ${ }^{2}$ Unit Environmental Modelling, Flemish Institute for Technological Research (VITO NV), Boeretang 200, \\ $2400 \mathrm{Mol}$, Belgium \\ ${ }^{3}$ Department of Bioscience Engineering, University of Antwerp, Groenenborgerlaan 171, 2020 Antwerp, Belgium \\ ${ }^{4}$ Department of Mathematical Modelling, Statistics and Bioinformatics, Ghent University, Coupure Links 653, \\ 9000 Ghent, Belgium
}

Correspondence to: M. Rezaei (meisam.rezaei@ugent.be; meisam.rezaei@ vito.be; meisam.rezaei1 @ gmail.com)

Received: 16 June 2015 - Published in Hydrol. Earth Syst. Sci. Discuss.: 20 July 2015

Revised: 6 January 2016 - Accepted: 15 January 2016 - Published: 29 January 2016

\begin{abstract}
Monitoring and modelling tools may improve irrigation strategies in precision agriculture. We used noninvasive soil moisture monitoring, a crop growth and a soil hydrological model to predict soil water content fluctuations and crop yield in a heterogeneous sandy grassland soil under supplementary irrigation. The sensitivity of the soil hydrological model to hydraulic parameters, water stress, crop yield and lower boundary conditions was assessed after integrating models. Free drainage and incremental constant head conditions were implemented in a lower boundary sensitivity analysis. A time-dependent sensitivity analysis of the hydraulic parameters showed that changes in soil water content are mainly affected by the soil saturated hydraulic conductivity $K_{\mathrm{s}}$ and the Mualem-van Genuchten retention curve shape parameters $n$ and $\alpha$. Results further showed that different parameter optimization strategies (two-, three-, four- or sixparameter optimizations) did not affect the calculated water stress and water content as significantly as does the bottom boundary. In this case, a two-parameter scenario, where $K_{\mathrm{S}}$ was optimized for each layer under the condition of a constant groundwater depth at $135-140 \mathrm{~cm}$, performed best. A larger yield reduction, and a larger number and longer duration of stress conditions occurred in the free drainage condition as compared to constant boundary conditions. Numerical results showed that optimal irrigation scheduling using the aforementioned water stress calculations can save up to $12-22 \%$ irrigation water as compared to the current irriga-
\end{abstract}

tion regime. This resulted in a yield increase of $4.5-6.5 \%$, simulated by the crop growth model.

\section{Introduction}

Efficient water use and optimal water supply to increase food and fodder productivity are of great importance when confronted with worldwide water scarcity, climate change, growing populations and increasing water demands (FAO, 2011). In this respect, irrigation efficiency which is influenced by the type of irrigation and irrigation scheduling is essential for achieving higher water productivity. In particular, precision irrigation is adopting new methods of accurate irrigation scheduling (Jones, 2004). Various irrigation scheduling approaches such as soil-based, weather-based, crop-based, and canopy temperature-based methods have been presented (Jones, 2004; Mohanty et al., 2013; Pardossi et al., 2009; Evett et al., 2008; Nosetto et al., 2012; Huo et al., 2012).

Numerical models are increasingly adopted in water resource planning and management. They contain numerical solutions of the Richards' equation (Richards, 1931) for water flow and root water uptake (Fernández-Gálvez et al., 2006; Vrugt et al., 2001; Skaggs et al., 2006) or contain reservoir cascade schemes (Gandolfi et al., 2006). Hydrological models require determination of hydraulic properties (Šimůnek and Hopmans, 2002), upper boundary conditions related to atmospheric forcing (evapotranspiration and pre- 
cipitation) (Brutsaert, 2005; Nosetto et al., 2012) and groundwater dynamics at the lower boundary of the soil profile (Gandolfi et al., 2006). Numerical models such as Hydrus 1D (Šimůnek et al., 2013) have been used in a wide range of irrigation management applications - for example, by Sadeghi and Jones (2012), Tafteh and Sepaskhah (2012), Akhtar et al. (2013) and Satchithanantham et al. (2014). The tool has been combined with crop-based models for accurate irrigation purposes and for predicting the crop productivity for cotton (Akhtar et al., 2013), vegetables and winter wheat (Awan et al., 2012). The degree of soil water stress was used for irrigation management by coupling a hydrological model (Hydrus 1D) with a crop growth model (WOFOST) for maize (Li et al., 2012) and wheat (Zhou et al., 2012). The importance of correct average representation of the soilplant-atmosphere interaction in numerical models has been stressed by Wollschlager et al. (2009). A combination of crop growth model and the hydrological model makes it possible to calculate crop yield reduction based on soil water stress derived by the hydrological model.

Direct measurement of hydraulic parameters may be inaccurate for predictions at the field scale (Verbist et al., 2012; Wöhling et al., 2008). As an alternative, parameters can be determined by inverse modelling. A single-objective inverse parameter estimation using the Levenberg-Marquardt optimization procedures has been used in different studies (Abbasi et al., 2004; Jacques et al., 2012; Šimůnek et al., 2013). A typical challenge in parameter optimization is the nonuniqueness of the parameters, leading to parameter identifiability problems (Hopmans et al., 2002). Non-uniqueness can be reduced by decreasing the number of parameters to be estimated based on a sensitivity analysis. Sensitivity analysis has been used to optimize parameter estimation, to reduce parameter uncertainty (Rocha et al., 2006), and to investigate the effects of various parameters or processes on water flow and transport (van Genuchten et al., 2012).

In this study, we used a combination of soil moisture monitoring and modelling to estimate hydraulic properties and to predict soil water content in a two-layered sandy soil for precision irrigation management purposes. The objective of this paper is to investigate the impact of parameter estimation and boundary conditions on the irrigation requirements, calculated using a soil hydrological model in combination with a crop growth model. The effect of changing bottom boundary conditions on model performance was evaluated in a first step (see the Supplement). A systematic local sensitivity analysis was then used to identify dominant hydraulic model parameters. This was followed by a model calibration using inverse modelling with field data to estimate the hydraulic properties. Finally, the degree of soil water stress was calculated with different parametrization scenarios to show to what extent hydrological model parameter choice and boundary conditions affect estimations of irrigation requirement and crop yield. It is acknowledged that there is no stress in soil water, whereas the water stress is in the plant, indeed. But similar to a large bulk of papers and reports, we used the soil water stress term in the present paper instead of water stress in the plants.

\section{Materials and methods}

\subsection{Description of the study site}

The study site is located in a sandy agricultural area at the border between Belgium and the Netherlands (with central coordinates $51^{\circ} 19^{\prime} 05^{\circ} \mathrm{N}, 05^{\circ} 10^{\prime} 40^{\circ} \mathrm{E}$ ), characterized by a temperate maritime climate with mild winters and cool summers. During the study period 2011-2013, the farmer cultivated grass. The farm is almost flat (less than $1 \%$ sloping up from NW to SE) and runoff is not considered to be important. The measured depth of the groundwater table was between 80 and $155 \mathrm{~cm}$ and the Ap horizon thickness was between 30 and $50 \mathrm{~cm}$ below the soil surface at various locations across the field depending on the topography. The field is partly drained by parallel drainage pipes which are placed at 10 to $20 \mathrm{~m}$ intervals and at around $90 \mathrm{~cm}$ below the soil surface (as measured in the ditch). Drainage pipes are connected to a ditch in the northwest border of the field. Figure 1 shows the location and layout of the field. The apparent soil electrical conductivity, $\mathrm{EC}_{\mathrm{a}}$, was measured at $5 \mathrm{~m}$ intervals between the measurement lines with a DUALEM-21S sensor (DUALEM, Milton, ON, Canada) corresponding to $0-100 \mathrm{~cm}$ depth of exploration. Then, $\mathrm{EC}_{\mathrm{a}}$ data were interpolated using ordinary point kriging (OK) to a 0.5 by $0.5 \mathrm{~m}$ grid to produce the field $\mathrm{EC}_{\mathrm{a}}$ map. More details about this methodology and its procedure can be found in Rezaei et al. (2016). Reel Sprinkler Gun irrigation (type Bauer rainstar E55, Röhren- und Pumpenwerk BAUER Ges.m.b.H., Austria) was used on a $290 \mathrm{~m}$ by $400 \mathrm{~m}$ field to improve crop growth in the sandy soil during dry periods in summer. The field was irrigated three times throughout each growing season (2012: $64.5 \mathrm{~mm}$ and 2013: $85.4 \mathrm{~mm}$ ).

Figure 2 shows the soil profile at a sensors location, indicated by the star on the map in Fig. 1 (see also next section), a typical Podzol (Zcg-Zbg type according to the Belgian soil classification or cambisol according to WRB; FAO, 1998) consisting of a uniform dark brown layer of sandy soil (Ap horizon, 0 to $33 \mathrm{~cm}$ ) with elevated organic matter content, followed by a yellowish to white sandy soil, including stones and gravels, ( $\mathrm{C} 1$ horizon, 33 to $70 \mathrm{~cm})$. A deeper horizon is light grey sandy soil (C2 horizon, 70 to $135 \mathrm{~cm}$ ), including more stones and gravels ( $\max 20 \%$ ), but having similar hydraulic properties as the $\mathrm{C} 1$ horizon. Maximum grass root density was found at about $6 \mathrm{~cm}$ and decreased from 6 to $33 \mathrm{~cm}$ (based on field observation during profile excavation). The properties of the two layers are summarized in Table 1. 


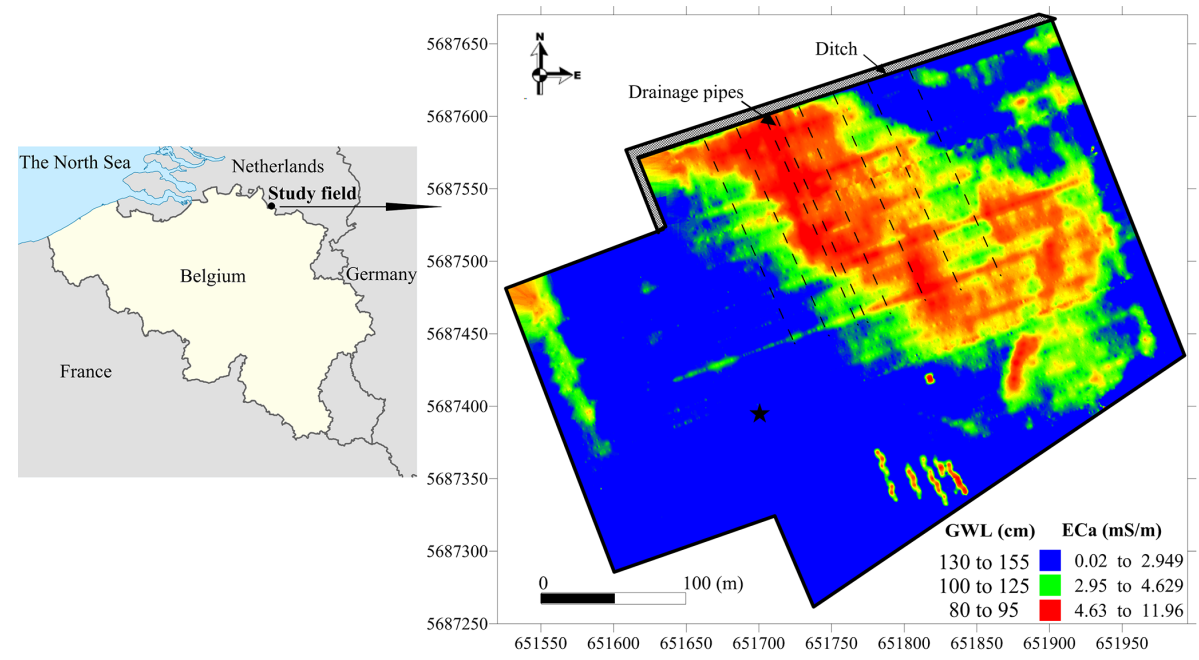

Figure 1. Geographical location of the experimental field and the map of the apparent soil electrical conductivity (EC $\mathrm{E}_{\mathrm{a}}$ ) of the study site corresponding to three different zones of groundwater levels (GWL). The black star on the $\mathrm{EC}_{\mathrm{a}}$ map indicates the sensor location.

Table 1. Average of soil properties of soil profile: $\theta_{\mathrm{r}}, \theta_{\mathrm{S}}$ are residual and saturated water content, respectively; $\alpha$ and $n$ are shape parameters for the van Genuchten-Mualem equation. $K_{\mathrm{S}}$ denotes the saturated hydraulic conductivity.

\begin{tabular}{|c|c|c|c|c|c|c|c|c|c|c|}
\hline & $\begin{array}{c}K_{\mathrm{S}} \\
\left(\mathrm{cm} \mathrm{h}^{-1}\right)\end{array}$ & $\begin{array}{c}\theta_{\mathrm{r}} \\
\left(\mathrm{cm}^{3}\right.\end{array}$ & $\begin{array}{c}\theta_{\mathrm{s}} \\
\left.\mathrm{m}^{-3}\right)\end{array}$ & $\begin{array}{c}\alpha \\
\left(\mathrm{cm}^{-1}\right)\end{array}$ & $n$ & $\mathrm{OC}$ & $\begin{array}{l}\text { Sand } \\
(\%)\end{array}$ & Silt & Clay & $\begin{array}{c}\rho_{\mathrm{b}} \\
\left(\mathrm{g} \mathrm{cm}^{-3}\right)\end{array}$ \\
\hline Topsoil & 9.59 & 0.09 & 0.39 & 0.017 & 2.72 & 2.08 & 91.65 & 7.0 & 1.35 & 1.57 \\
\hline Subsoil & 4.74 & 0.03 & 0.31 & 0.021 & 2.34 & 0.18 & 95.7 & 3.1 & 1.2 & 1.76 \\
\hline
\end{tabular}

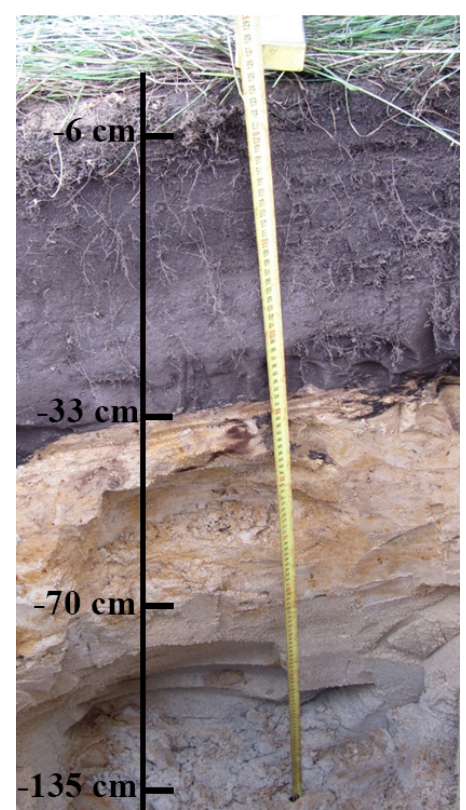

Figure 2. Two-layered typical soil profile of the field close to the location of the sensor.

\subsection{Field monitoring system}

The site was equipped with two weather stations (type CM10, Campbell Scientific Inc., UT, USA), one in the study field and another $100 \mathrm{~m}$ away from the field. Soil water content was recorded (from 1 March until 25 November in both 2012 and 2013) using a water content profile probe (type EasyAG50, Sentek Technologies Ltd., Stepney, Australia), placed vertically, that measures soil water content at 10,20 , 30,40 and $50 \mathrm{~cm}$ depths. The weather stations were connected to a CR800 data logger (Campbell Scientific Inc., UT, USA) and the water content profile probe provided the soil water content wirelessly. All measurements were taken on an hourly basis and an hourly reference evapotranspiration was calculated based on the Penman-Monteith equation (Allen et al., 1998) using weather station data. The amount of irrigation was derived by subtracting measurements of rain gauges of the field's weather station (i.e. rainfall and irrigation) and the local meteorological station (i.e. only rainfall) outside the study field. Grass yield was measured at each harvesting time (four times in each growing season) across the field (Fig. 3).

At the sensor location (indicated by the star on the map in Fig. 1), duplicate undisturbed $\left(100 \mathrm{~cm}^{3}\right.$ Kopecky rings, Eijkelkamp Agrisearch Equipment, Giesbeek, The Netherlands) soil samples were taken to determine the soil saturated 

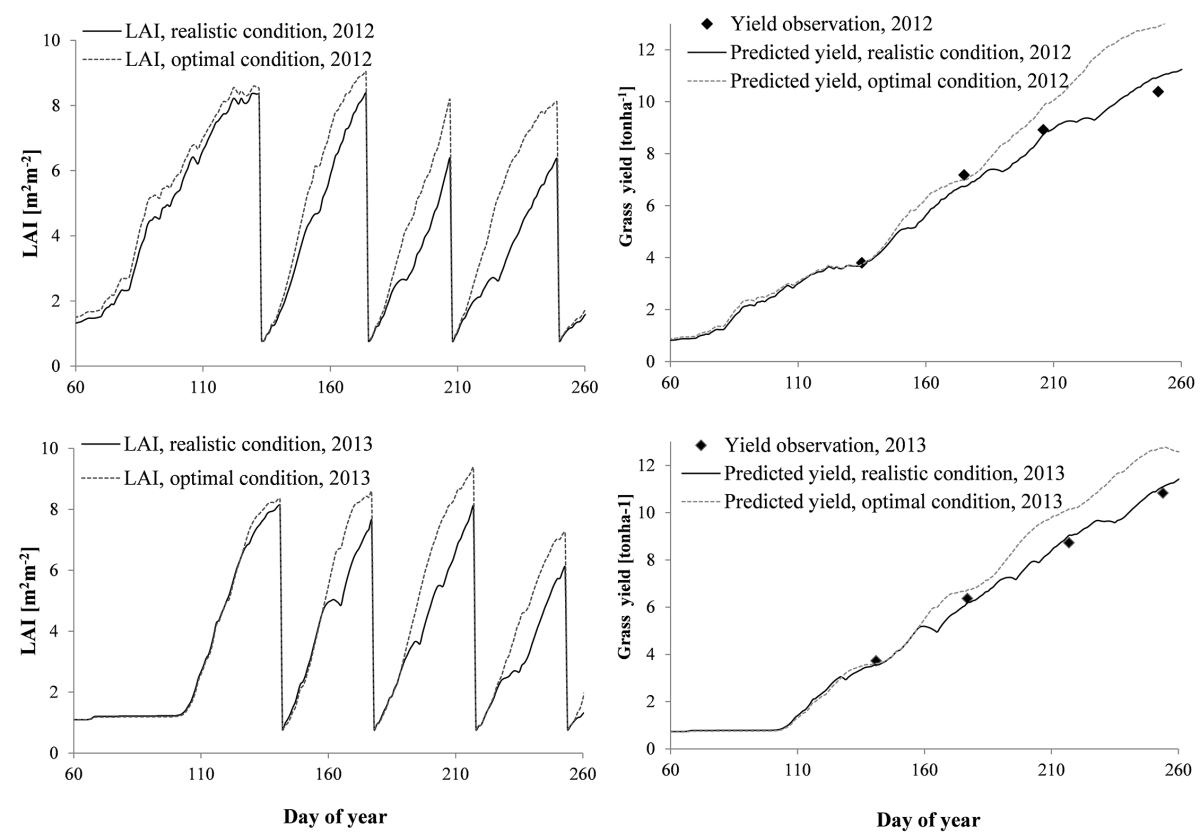

Figure 3. Predicted leaf area index, LAI and grass yield using the LINGRA-N model for 2012 and 2013.

hydraulic conductivity and water retention curve, and one disturbed sample to measure soil properties such as texture, dry bulk density and organic matter, from the Ap (topsoil) and C (subsoil) horizons in June 2013. Groundwater depth at the sensor location was measured four times on 4 June and 5 October 2012 (140 and $136 \mathrm{~cm}$, respectively), and 24 June and 25 October 2013 (135 and $133 \mathrm{~cm}$, respectively) using augering.

The saturated hydraulic conductivity $\left(K_{\mathrm{s}}\right)$ was determined using a constant head laboratory permeameter (M1-0902e, Eijkelkamp Agrisearch Equipment, Giesbeek, The Netherlands). The soil water retention curve (SWRC, $\theta(h)$ ), was determined using the sandbox method (Eijkelkamp Agrisearch Equipment, Giesbeek, the Netherlands) up to a matric head of $-100 \mathrm{~cm}$ and the standard pressure plate apparatus (Soilmoisture Equipment, Santa Barbara, CA, USA) for matric heads equal to or below $-200 \mathrm{~cm}$, following the procedure outlined in Cornelis et al. (2005). Bulk density was obtained by drying volumetric soil samples $\left(100 \mathrm{~cm}^{3}\right)$ at $105^{\circ} \mathrm{C}$. Particle size distribution of the mineral component was obtained using the pipette method for clay and silt fractions and the sieving method for sand particles (Gee and Bauder, 1986). The organic matter content was determined by the method of Walkley and Black (1934).

Soil hydraulic properties were determined according to the van Genuchten (1980) and Mualem (1976) conductivity model (MVG model). The parameters of the water retention equation were fitted to the observed data set using the RETC, version 6.02 (van Genuchten et al., 1991). The MVG model
(Mualem, 1976; van Genuchten, 1980) is given by

$$
\begin{aligned}
& S_{\mathrm{e}}=\frac{\theta-\theta_{\mathrm{r}}}{\theta_{\mathrm{s}}-\theta_{\mathrm{r}}} \\
& S_{\mathrm{e}}(h)=1 \quad h \geq 0 \\
& S_{\mathrm{e}}(h)=\left(1+|\alpha h|^{n}\right)^{-m} h<0 ; \quad \text { where } m=1-\frac{1}{n} \\
& K\left(S_{\mathrm{e}}\right)=K_{\mathrm{s}} S_{\mathrm{e}}^{l}\left[1-\left(1-S_{\mathrm{e}}^{\frac{1}{m}}\right)^{m}\right]^{2},
\end{aligned}
$$

where $\theta_{\mathrm{s}}, \theta_{\mathrm{r}}$ and $\theta$ are the saturated, residual and actual volumetric water content respectively $\left(\mathrm{cm}^{3} \mathrm{~cm}^{-3}\right), \alpha$ is the inverse of air entry value $\left(\mathrm{cm}^{-1}\right), n$ is a pore size distribution index $>1, m=1-1 / n$ (dimensionless) $S_{\mathrm{e}}$ is the effective saturation (dimensionless), and $l$ is a pore connectivity and tortuosity parameter in the hydraulic conductivity function, which is assumed to be 0.5 as an average for many soils (Mualem, 1976).

\subsection{Modelling at monitoring locations}

\subsubsection{Simulation of leaf area index and grass yield}

The simple generic crop growth model, LINGRA-N (Wolf, 2012), which can calculate grass growth and yields under potential (i.e. optimal), water-limited (i.e. rain fed) and nitrogen-limited growing conditions, was used to calculate the leaf area index (LAI) and grass yield. This tool was calibrated and tested for perennial rye grass and natural annual grass over Europe (Barrett et al., 2004; Schapendonk et al., 1998). LINGRA-N simulates the growth of a grass crop as a function of intercepted radiation, temperature, light use effi- 
ciency and available water (Wolf, 2012). The LAI and crop growth simulations were carried out from 1 January 2012 to 31 December 2013. The model calculated LAI and yield on a daily time intervals using daily weather data, solar radiation $\left(\mathrm{kJ} \mathrm{m}^{-2} \mathrm{~d}^{-1}\right)$, minimum temperature $\left({ }^{\circ} \mathrm{C}\right)$, maximum temperature $\left({ }^{\circ} \mathrm{C}\right)$, vapour pressure $(\mathrm{kPa})$, wind speed $\left(\mathrm{m} \mathrm{s}^{-1}\right)$ and precipitation $\left(\mathrm{mm} \mathrm{d}^{-1}\right)$. A grass crop data file is available mainly derived from WOFOST. Soil data for our soil were produced using measured values of soil moisture content at air dry $(\mathrm{pF}=6)$, wilting point $(\mathrm{pF}=4.2)$, field capacity $(\mathrm{pF}=2.3)$ and at saturation and also percolation to deeper soil layers $\left(\mathrm{cm} \mathrm{day}^{-1}\right)$ in the laboratory. The maximum rooting depth was adjusted to $40 \mathrm{~cm}$. Irrigation supply was imposed at the specific applied times with optimal nitrate application. The simulated LAI was scaled to an hourly basis using linear interpolation between two adjacent simulated daily values of LAI. The model was run for optimal (no water limitation) and realistic conditions (actual water inlet i.e. irrigation and rainfall) for each growing season. Figure 3 represents predicted LAI and grass yield of 2012 and 2013.

\subsubsection{Simulation of water flow}

The simulated soil profile in the hydrological model extends to $150 \mathrm{~cm}$ depth and is divided into two layers: Layer $1(0$ to $33 \mathrm{~cm}$ ) and Layer 2 (33 to $150 \mathrm{~cm})$. Simulation of root water uptake and water flow, which is assumed to be in the vertical direction in the vadose zone, was carried out for two growing seasons (from 1 March until 25 November in 2012 and 2013) using Hydrus 1D version 4.16 which solves the 1-D Richards' equation:

$\frac{\partial \theta}{\partial t}=\frac{\partial}{\partial z}\left[K(h)\left(\frac{\partial h(\theta)}{\partial z}+1\right)\right]-S(h)$,

where $\theta$ is the volumetric water content $\left(\mathrm{cm}^{3} \mathrm{~cm}^{-3}\right), t$ is time (h), $z$ is the radial and vertical space coordinate taken positive downward $(\mathrm{cm}), K(h)$ is the unsaturated hydraulic conductivity function $\left(\mathrm{cm} \mathrm{h}^{-1}\right), h$ is the pressure head $(\mathrm{cm})$ and $S(h)$ represents a sink term $\left(\mathrm{cm}^{3} \mathrm{~cm}^{-3} \mathrm{~h}^{-1}\right)$, defined as the volume of water removed from a unit volume of soil per unit time due to plant water uptake.

To solve Eq. (5), the MVG soil hydraulic model (Eqs. 14) without air entry value and without hysteresis was used. The initial pressure head distribution was calculated using the inverse of Eq. (3), $h\left(S_{\mathrm{e}}\right)$, from the measured initial water content of each observation node. These point values were then interpolated linearly from the deepest observation node to the groundwater level $(h=0, \mathrm{GWL})$. The pore connectivity parameter of the MVG model was fixed at $l=0.5$. The upper condition for water flow was an atmospheric boundary condition - based on rainfall and irrigation water supply, LAI calculated by LINGRA-N (see Sect. 2.3.1) and reference evapotranspiration $\left(\mathrm{ET}_{\mathrm{o}}\right)$ - with surface runoff. The model performance was assessed using various implemented bottom boundary conditions, i.e. free drainage and incremental constant head conditions, as a manual sensitivity analysis (see the Supplement). The Feddes model (Feddes et al., 1978) without solute stress was used for root water uptake. The default grass parameters values provided by Hydrus 1D were used (Taylor and Ashcroft, 1972).

\subsection{Soil water stress and yield reduction}

In the Feddes model (Feddes et al., 1978) the sink term of Richards' Eq. (5), $S(h)$, is specified in terms of quantify potential root water uptake and water stress as

$S(h)=w(h) R(x) T_{\mathrm{p}}$,

where $R(x)$ is the root distribution function $(\mathrm{cm}), T_{\mathrm{p}}$ is potential transpiration $\left(\mathrm{cm} \mathrm{h}^{-1}\right)$ and $w_{(h)}$ is the water stress response function $\left(0 \leq w_{(h)} \leq 1\right)$ which prescribes the reduction in uptake that occurs due to drought stress. Crop-specific values of this reduction function are chosen from the default Hydrus data set. The actual plant transpiration is calculated numerically, as

$T_{\mathrm{a}}=\int_{L_{\mathrm{r}}} S(h) \mathrm{d} x=T_{\mathrm{p}} \int_{L_{\mathrm{r}}} w(h) R(x) \mathrm{d} x$,

where $L_{\mathrm{r}}$ is the rooting depth $(\mathrm{cm})$

By assuming root water uptake is equal to actual transpiration, the ratio of actual to potential transpiration by the root uptake was introduced as a degree of water stress, DWS (Jarvis, 1989), as

$\mathrm{DWS}=\frac{T_{\mathrm{a}}}{T_{\mathrm{p}}}=\int_{L_{\mathrm{r}}} w(h) R(x) d x$.

The effect of the boundary conditions and parameter uncertainty on soil water stress was evaluated using the ratio between the calculated actual water uptake/actual transpiration and the potential transpiration provided by the model ( $\mathrm{Li}$ et al., 2012; Zhou et al., 2012). In optimal and stress-free conditions, this ratio should be (close to) unity ( $>0.90$ of maximum reference evapotranspiration).

The ratio between actual crop evapotranspiration and potential evapotranspiration was introduced as a water stress factor equal to the crop yield reduction due to water shortage (Doorenbos and Kassam, 1979), given as

$1-\frac{Y_{\mathrm{a}}}{Y_{\mathrm{m}}}=K_{y}\left(1-\frac{\mathrm{ET}_{\mathrm{a}}}{\mathrm{ET}_{\mathrm{p}}}\right)$,

where $Y_{\mathrm{a}}$ is actual crop yield, $Y_{\mathrm{m}}$ is the maximum crop yield in optimal condition, $K_{y}$ is the crop yield factor (for grass $\left.K_{y}=1\right), \mathrm{ET}_{\mathrm{a}}$ is actual crop evapotranspiration estimated by the model. The $Y_{\mathrm{m}}$ value was simulated using LINGRA-N in optimal condition (no water stress) for 2012 and 2013 growing seasons. $\mathrm{ET}_{\mathrm{p}}$ is potential evapotranspiration and can be 
calculated from the reference evapotranspiration by

$\mathrm{ET}_{\mathrm{p}}=\mathrm{ET}_{0} \times K_{\mathrm{c}}$,

where $K_{\mathrm{c}}$ is the crop coefficient and equal to 1 , assuming that grass at our site did not differ much from the reference crop. Accordingly, crop yield reduction of each scenario was calculated using Eq. (9) for both periods to show to what extent different scenarios affect soil water stress and crop yield.

\subsection{Sensitivity analysis}

The effect of each input factor or parameter on the model output is determined by a local sensitivity analysis (SA), using a one-at-a-time (OAT) approach. We used this approach because it allows a clear identification of single-parameter effects. Relevant parameters have major effects on output variables with only a small change in their value (Saltelli et al., 2008). SA is, among other purposes, used to find the most relevant parameters which enable a reduction of the number of parameters that need to be optimized. In a local SA, only the local properties of the parameter values are taken into account, in contrast to global SA which computes a number of local sensitivities. Since the interest in this study goes specifically to the measured (parameter) values in the field, a local SA is chosen. Furthermore, an OAT approach (local or global) does not provide direct information about higher- and total-order parameter interaction as is provided by variancebased SA (Saltelli et al., 2008). However, by evaluating the parameter sensitivities in time, insight is given about potential interaction when similar individual effects are observed. The latter can be quantified by a collinearity analysis (Brun et al., 2001), but will be done graphically in this contribution. A dynamic sensitivity function can be written as follows:

$\mathrm{SF}(t)=\frac{\partial y(t)}{\partial x}$,

where $\mathrm{SF}(t), y(t)$ and $x$ denote the sensitivity function, output variable and parameter respectively. If an output variable (y) significantly changes (evaluated by calculating the variance or coefficient of determination or by visualizing in a scatter plot) due to small changes of the parameter of interest $x$, it is called a sensitive parameter.

This partial derivative can be calculated analytically or numerically with a finite difference approach by a local linearity assumption of the model on the parameters. Local sensitivity functions evaluate the partial derivative around the nominal parameter values. The central differences of the sensitivity function are used to rank the parameter sensitivities and can be expressed as follows:

$$
\begin{aligned}
& \Delta x_{j}=p_{f} \cdot x_{j} \\
& \mathrm{CAS}=\frac{\partial y(t)}{\partial x}=\frac{y\left(t, x_{j}+\Delta x_{j}\right)-y\left(t, x_{j}-\Delta x_{j}\right)}{2 \Delta x_{j}} \\
& \mathrm{CTRS}=\frac{\partial y(t)}{\partial x} \frac{x_{j}}{y} \quad \mathrm{CPRS}=\frac{\partial y(t)}{\partial x} x_{j},
\end{aligned}
$$

where $p_{f}$ is the perturbation factor, $x_{j}$ is the parameter value and $\Delta x_{j}$ is the perturbation, CAS is the Central Absolute Sensitivity, CTRS is the Central Total Relative Sensitivity analysis, and CPRS is a Central Parameter Relative Sensitivity. Since the parameters and variables have different orders of magnitude for which the sensitivity is calculated, direct comparison of the sensitivity indices with CAS is not possible. Hence, recalculation towards relative and comparable values is needed. In order to compare the sensitivity of the different parameters towards the different variables, CTRS is preferred. CPRS is sufficient when the sensitivity of different parameters is compared for a single variable, i.e. soil water content. Here, a dynamic (time-variable) local sensitivity analysis was conducted by linking Eqs. (11)-(14), programmed in Python software (https://www.python.org/) to Hydrus 1D.

Given the output accuracy of Hydrus 1D (0.001), a perturbation factor of 0.1 was chosen. To carry out the SA, each hydraulic parameter $\left(K_{\mathrm{s}}, \theta_{\mathrm{r}}, \theta_{\mathrm{s}}, \alpha\right.$, and $\left.n\right)$ in each layer was varied (measured value \pm perturbation factor) and its CTRS was calculated (Eqs. 13-14), while the values of other parameters were fixed to the measured values. The model was run in forward mode 20 times, i.e. 10 runs for each layer and two runs for each parameter. A weak direct effect of a parameter in SA is denoted by low absolute values close to 0 . A positive effect is expressed by a positive value and a negative effect by a negative value.

\subsection{Model calibration and validation}

\subsubsection{Model calibration}

For accurate parameter estimation, a longer period such as a growing season (i.e. 2012) with several drying and wetting events was selected. This was also suggested by Wöhling et al. $(2008,2009)$. Therefore, the period between 1 March 2012 (00:00 CET) and 25 November 2012 (23:00 h) was used as the calibration period. We used a time interval of $2 \mathrm{~h}$, resulting in 12960 soil water content records for four depths (as data for inverse solution), based on hourly precipitation and evaporation input data. Based on our experience this number of data is sufficient for optimization purposes. The objective functions were soil water content and water retention data for both soil layers with unit weighting. In the calibration, we optimized only the values of the most sensitive parameters $\left(K_{\mathrm{s}}, n\right.$ and $\alpha$ ) of the two layers, taking initial values of hydraulic parameters for each layer equal to the values estimated by the RETC program for the independent field 
samples, while keeping the insensitive hydraulic parameters $\left(\theta_{\mathrm{s}}, \theta_{\mathrm{r}}\right)$ fixed to the measured values. Thirty-seven parameter optimization scenarios were selected and analysed to identify correlations among optimized parameters and to identify the most influential parameter sets on soil water stress and water content in different lower boundary conditions. The 37 scenarios comprised optimizing all six parameters simultaneously (one scenario), four parameters (nine scenarios), three parameters (18 scenarios) and two parameters (nine scenarios). Finally, the best-performing parameter set - based on performance criteria, the correlation between optimized parameters (non-uniqueness of the parameter sets) and the visual inspection of simulated and observed soil water content - was selected for validation using independent data from 2013 (from 1 March until 12 September 2013).

\subsubsection{Model evaluation and statistical analysis}

The performance of models can be evaluated with a variety of statistics (Neuman and Wierenga, 2003). It is known that there is no efficiency criterion which performs ideally. Each of the criteria has specific pros and cons which have to be taken into account during model calibration and evaluation. It is suggested to use a combination of different efficiency criteria to assess of the absolute or relative volume error (Krause et al., 2005). The root-mean-square errors (RMSE), the coefficient of determination $\left(r^{2}\right)$ and the Nash-Sutcliffe coefficient of model efficiency $\left(C_{\mathrm{e}}\right)$ (American Society of Civil Engineers, 1993) are popular and widely used performance criteria to evaluate the difference between observed and modelled data (Wöhling and Vrugt, 2011; Verbist et al., 2009, 2012; Gandolfi et al., 2006; Vrugt et al., 2004; Wollschlager et al., 2009; Nasta et al., 2013). They are calculated as follows:

$$
\begin{aligned}
& C_{\mathrm{e}}=1-\frac{\sum_{i=1}^{n}\left(O_{i}-S_{i}\right)^{2}}{\sum_{i=1}^{n}\left(O_{i}-\bar{O}\right)^{2}} \\
& r^{2}=\left(\frac{\sum_{i=1}^{n}\left(O_{i}-\bar{O}\right)\left(S_{i}-\bar{S}\right)}{\sqrt{\sum_{i=1}^{n}\left(S_{i}-\bar{S}\right)^{2} \sum_{i=1}^{n}\left(O_{i}-\bar{O}\right)^{2}}}\right)^{2} \\
& \mathrm{RMSE}=\sqrt{\frac{\sum_{i}^{n}\left(O_{i}-S_{i}\right)^{2}}{n}},
\end{aligned}
$$

where $O$ and $S$ are observed and simulated values at time/place $i$, respectively.

$C_{\mathrm{e}}$ and $r^{2}$ are considered to be satisfactory when they are close to 1 , while RSME should be close to $0 . C_{\mathrm{e}}$ may result in negative values when the mean square error exceeds the variance (Hall, 2001).

\subsection{Irrigation scheduling}

The value of soil water stress, and the number and the duration of stress periods was calculated for two growing seasons
(2012 and 2013), as an indicator for the performance of the irrigation scheduling (van Dam et al., 2008). To optimize the irrigation scheduling (timing of application), the actual water supply (all irrigation events) was deleted from the model input of the hydrological model. Secondly, the LAI simulated with the LINGRA-N for optimal conditions (no water stress) was used as a variable in the hydrological model. Then, the hydrological model with a constant bottom boundary condition was run with the new input variables to elucidate water stress without actual water supply (see the Supplement). Subsequently, the required irrigation was added to the precipitation at the beginning of each water stress period to exclude water stress from the simulations. To simulate crop yield at the optimized condition, the new precipitation variables (rainfall and required irrigation) were used in LINGRA-N model. The optimal yield obtained using the optimized irrigation scheduling was compared to the actual (simulated and measured) yield of current irrigation management practices.

\section{Results and discussion}

\subsection{Parameter sensitivity analysis}

Due to the variable rainfall, irrigation, evapotranspiration and drainage, the soil water content changes in the soil profile, and, consequently, parameter sensitivities are time dependent. The soil water content has a low sensitivity to $\theta_{\mathrm{s}}$ and $\theta_{\mathrm{r}}$, especially for the second layer. Low sensitivities to $\theta_{\mathrm{r}}$ have been reported by others (Kelleners et al., 2005; Mertens et al., 2006; Wöhling et al., 2008).

Figure 4 illustrates the results of the sensitivity analysis as a function of time for the most influential parameters $\alpha, n$ and $K_{\mathrm{S}}$, and for both soil layers as depicted by the suffix 1 for layer 1 and suffix 2 for layer 2. A weak direct effect of a parameter is reflected by low absolute values (close to 0 ).

The results show for all parameters a general change in sensitivity with time with the seasonal changes in irrigation application and rainfall. Generally, all soil hydraulic parameters showed higher sensitivity in dry periods as compared to wet periods. On the other hand, there is a clear effect of parameter variability in layer 1 on water content estimation at $10 \mathrm{~cm}$, and the effect is slightly declining at 20 and $30 \mathrm{~cm}$, which suggests the great importance and influence of upper boundary variables, especially evapotranspiration. Similar results were observed by Rocha et al. (2006). They found that soil water content and pressure heads were most sensitive to hydraulic parameters variation in the dry period near the soil surface using local sensitivity analysis of Hydrus.

Soil water content is sensitive to variations of $\alpha, n$ and $K_{\mathrm{S}}$ in both layers. The sensitivity is the largest for $n, \alpha$ and less so for $K_{\mathrm{S}}$ in the first layer. For the second layer, soil water content was most sensitive to $\alpha$ followed by $n$ and $K_{\mathrm{s}}$. Abbasi et al. (2003) reported that $n, \theta_{\mathrm{S}}$ and $K_{\mathrm{S}}$ were the most sensitive parameters in their study and that this sensitivity 

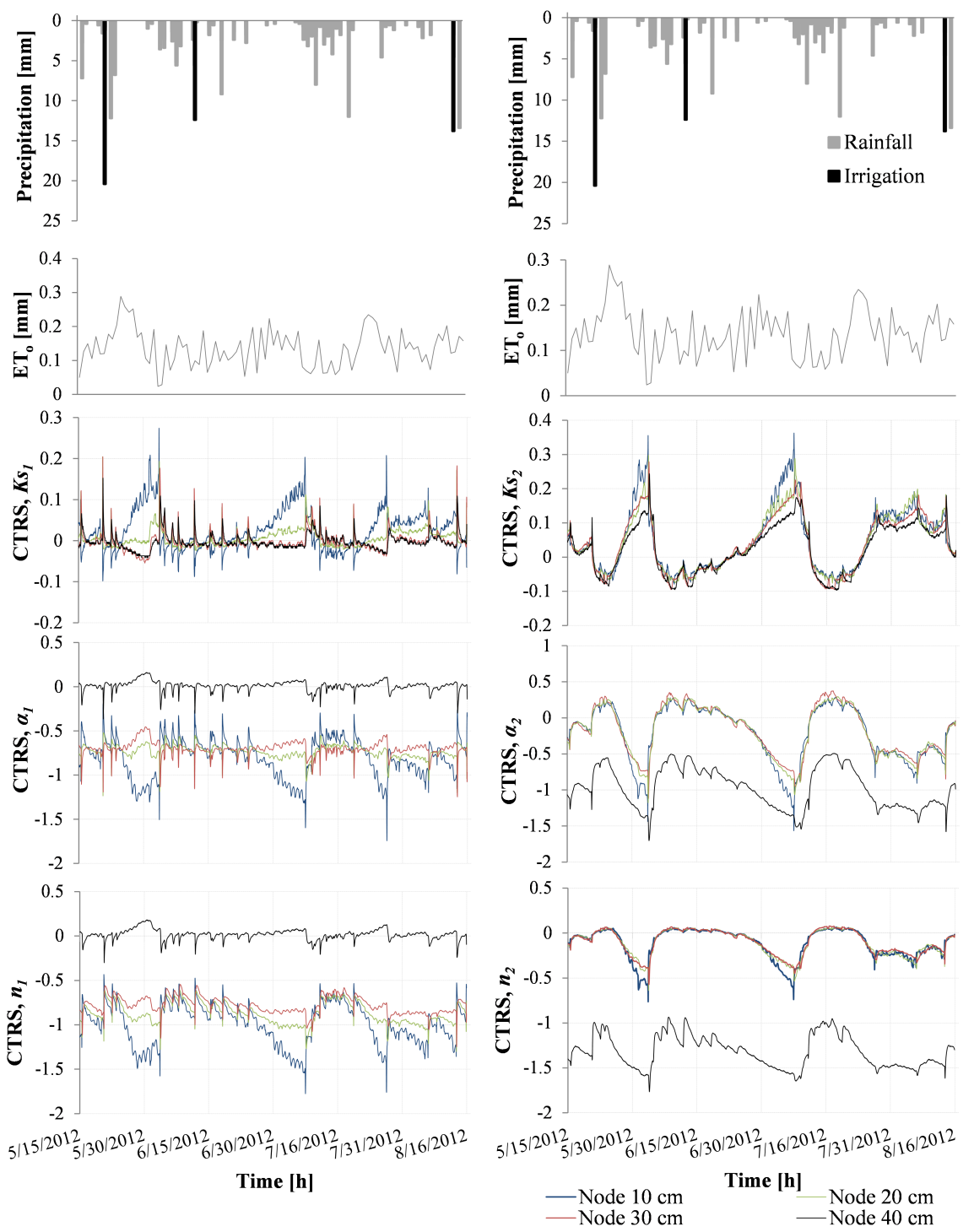

Figure 4. Parameter sensitivity as a function of time. The numbers 1 and 2 correspond to the first and second layer, respectively.

was more pronounced in deeper parts, however they also observed some sensitivity near the soil surface during the drier conditions. The most sensitive parameters were $\theta_{\mathrm{s}}, n$ and $\alpha$ and least sensitive parameter was $K_{\mathrm{S}}$ in the study by Schneider et al. (2013) using Hydrus 1D. They found large interaction (correlation) among sensitive parameters. In contrast, Wegehenkel and Beyrich (2014) reported that soil water content predictions were most sensitive to $\theta_{\mathrm{r}}$ and $\theta_{\mathrm{s}}$ and least sensitive to $\alpha, n$ and $K_{\mathrm{s}}$ input parameters using Hydrus 1D. Similarly, Caldwell et al. (2013) found that $\theta_{\mathrm{r}}, n$ and $l$ were sensitive and $\theta_{\mathrm{s}}, \alpha$ and $K_{\mathrm{S}}$ were insensitive to water content simulation. In dry periods, there is a general negative correlation between $n$ and $\alpha$ on the one hand and soil water content on the other hand, whereas a positive correlation exists between $K_{\mathrm{S}}$ and soil water content (Fig. 4). Figure 4 shows that in the first layer, the soil water content is more influenced by rainfall at $10 \mathrm{~cm}$ than at $30 \mathrm{~cm}$ (higher and lower sensitivity for observation nodes 10 and $30 \mathrm{~cm}$, respectively, within first layer).

The fact that the model predictions in the upper part of the soil profile are extremely sensitive to variations in hydraulic parameters in dry periods, is of great importance to irrigation management. To improve the timing of irrigation in these crucial periods, numerical soil models that are used to determine irrigation requirement, need to be well parametrized for $\alpha, n$ and $K_{\mathrm{s}}$.

\subsection{Model calibration}

Since soil water content prediction was insensitive to the parameters $\theta_{\mathrm{S}}$ and $\theta_{\mathrm{r}}$, they were fixed to the measured (initial) 
Table 2. Optimized values of hydraulic parameters for the optimization scenarios yielding uncorrelated parameters (except for reference scenario with six optimized parameters). Values indicated in italic are values fixed to the measured values close to the sensor location. Numbers in parentheses represent the standard errors of optimized parameter.

\begin{tabular}{|c|c|c|c|c|c|c|c|}
\hline \multirow[t]{2}{*}{ Boundary condition } & \multirow{2}{*}{$\begin{array}{l}\text { Number of } \\
\text { optimized } \\
\text { parameters }\end{array}$} & \multicolumn{3}{|c|}{ First soil layer } & \multicolumn{3}{|c|}{ Second soil layer } \\
\hline & & $\alpha_{1}\left(\mathrm{~cm}^{-1}\right)$ & $n_{1}$ & $K_{\mathrm{s} 1}\left(\mathrm{~cm} \mathrm{~h}^{-1}\right)$ & $\alpha_{2}\left(\mathrm{~cm}^{-1}\right)$ & $n_{2}$ & $K_{s 2}\left(\mathrm{~cm} \mathrm{~h}^{-1}\right)$ \\
\hline \multirow{4}{*}{ Constant head $(-140 \mathrm{~cm})$} & 6 & $0.023(0.0004)$ & $2.14(0.02)$ & $2.87(0.111)$ & $0.022(0.0006)$ & $2.15(0.034)$ & $1.95(0.14)$ \\
\hline & 4 & 0.017 & $2.64(0.003)$ & $1.54(0.028)$ & $0.020(0.00005)$ & 2.34 & $1.43(0.026)$ \\
\hline & 3 & 0.017 & 2.72 & $1.39(0.026)$ & $0.020(0.00005)$ & 2.34 & $1.65(0.031)$ \\
\hline & 2 & 0.017 & 2.72 & $1.20(0.023)$ & 0.021 & 2.34 & $2.17(0.044)$ \\
\hline Constant head $(-120 \mathrm{~cm})$ & 2 & 0.017 & 2.72 & $3.45(0.162)$ & 0.021 & 2.34 & $0.75(0.0107)$ \\
\hline \multirow{4}{*}{ Free drainage } & 6 & $0.036(0.0007)$ & $1.45(0.003)$ & $16.68(0.48)$ & $0.013(0.0005)$ & $1.59(0.013)$ & $5.10(0.51)$ \\
\hline & 4 & 0.017 & $1.53(0.003)$ & $5.09(0.12)$ & $0.003(0.00013)$ & 2.34 & $0.33(0.005)$ \\
\hline & 3 & 0.017 & 2.72 & $0.97(0.02)$ & $0.017(0.00008)$ & 2.34 & $0.22(0.004)$ \\
\hline & 2 & 0.017 & 2.72 & $0.86(0.022)$ & 0.021 & 2.34 & $0.39(0.004)$ \\
\hline
\end{tabular}

values (Table 1). Similar strategies were used by Verbist et al. (2012) and Schwartz and Evett (2002).

The model was run inversely using time series of soil water content with values for $\alpha, n$ and $K_{\mathrm{s}}$ being optimized for the two layers (i.e. six-parameter optimization scenario). A significant correlation appears between optimized $\alpha$ and $K_{\mathrm{S}}$ for both layers (layer 1: $r=0.85$; layer 2: $r=0.95$ constant head; and layer 1: $r=0.82$; layer 2: $r=0.80$ free drainage) and between optimized $n$ and $\alpha$ (both layers: $r=-0.99$ constant head; and layer 1: $r=-0.83$ and layer $2: r=-0.84$ free drainage) within each layer, but not between layers. On the other hand, there is a significant correlation between $n$ and $K_{\mathrm{S}}$ in both layers (layer 1: $r=-0.85$; layer 2: $r=-0.94$ constant head; and layer 1: $r=-0.75$; layer $2: r=-0.98$ free drainage). This means that $\alpha, n$ and $K_{\mathrm{s}}$ within one layer cannot be determined independently and different sets of correlated parameters lead to very similar predictions of soil water content. The high correlation between optimized parameters within a layer leads to a large uncertainty of the final parameter estimates (Hopmans et al., 2002). To avoid non-uniqueness of the inverse solution (Šimůnek and Hopmans, 2002), 36 additional systematic four-, three- and twoparameter optimizations were conducted. All optimizations resulting in correlations among the optimized parameters were removed and only the optimization scenarios with the uncorrelated parameters were kept. This resulted in parameter values as shown in Table 2 for a constant head corresponding to a groundwater depth of $-140 \mathrm{~cm}$ and free drainage. For comparison purposes, the six-parameter scenario (all parameters optimized) and only the best-performing optimization with two parameters is presented for the other boundary condition (i.e. $\mathrm{GWL}=-120 \mathrm{~cm}$ ).

The performance results of the parameter optimizations according to the performance criteria for all scenarios with uncorrelated parameters and different boundary conditions are presented in Table 3, together with the performance of the six-parameter scenario. The results show that a twoparameter optimization (optimizing only $K_{\mathrm{S}}$ in both layers) performs equally well as compared to a six-, four- or threeparameter scenario for all performance criteria and observation depths. However, parameters in the six-parameter scenario are considered unidentifiable due to their correlations. In this case, the model was not able to find a global minimum but found a local minimum (Levenberg-Marquardt method) due to the high dimensionality of the problem (Ritter et al., 2003) and the large uncertainty of the optimized values.

Large differences in model performance were obtained when using free drainage or constant head conditions (Table 3). After optimization, the $r^{2}$ for different free drainage and constant head conditions and various optimization scenarios was similar, while $C_{\mathrm{e}}$ and RSME were different. Overall, the performance of the model to predict soil water content at $40 \mathrm{~cm}$ was lowest. The model performs well for the 10,20 and $30 \mathrm{~cm}$ depths where the plant roots are concentrated and which are consequently the most critical in terms of irrigation optimization. The model with a constant head $(-140 \mathrm{~cm})$ clearly performed better than the free drainage boundary condition. The smallest differences were detected at the top node $(10 \mathrm{~cm})$ compared to deeper nodes in constant head and free drainage conditions. The optimization approach showed that the free drainage condition was unsuccessful to predict soil water content sufficiently well, in agreement with observations, even using different parameter estimations.

The two-parameter scenario requires fewer parameters (one parameter for each layer) to be optimized, performs better as compared to the uncalibrated model (see Supplementary Material) and is therefore to be preferred. Large confidence limits indicate uncertain estimations of a particular parameter (Šimůnek and Hopmans, 2002). The optimized $K_{\mathrm{S}}$ with $95 \%$ confidence limits (CL) for the first and second layer were $1.20(1.15-1.24) \mathrm{cm} \mathrm{h}^{-1}$, and 2.17 

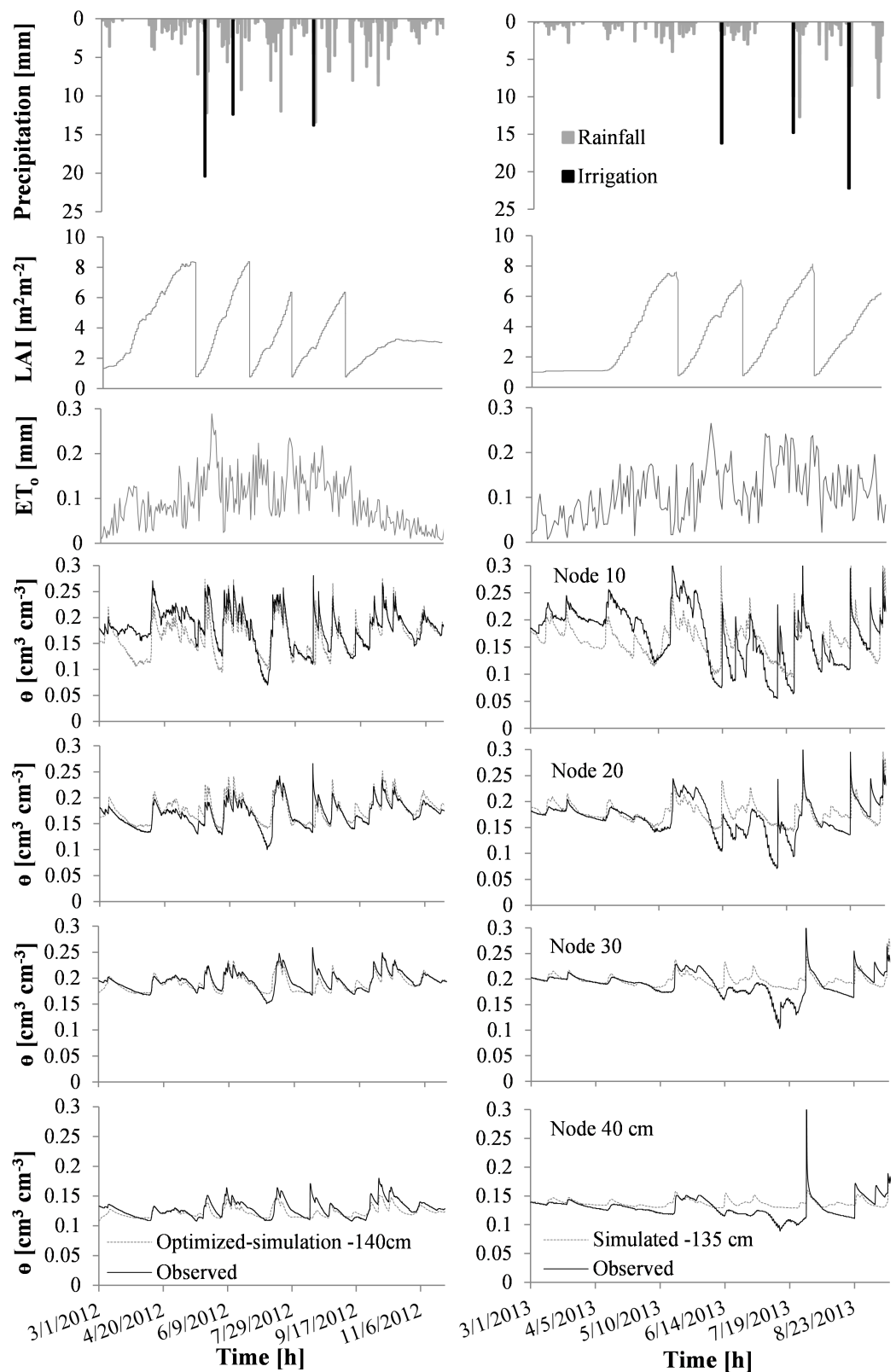

Figure 5. Observed and simulated time series of soil water content with calibration using the two-parameter $K_{\mathrm{S}}$ scenario for 2012 and validation results of 2013 .

(2.06-2.26) $\mathrm{cm} \mathrm{h}^{-1}$, respectively, in the two-parameter scenario with $-140 \mathrm{~cm}$ GWL. Therefore, this optimization result was considered the best and was chosen for the evaluation run.

\subsection{Model evaluation}

The validation results (using the same hydraulic parameter values as in the calibration period) under different upper (rainfall and water supply, $\mathrm{ET}_{\mathrm{o}}$, LAI) and lower (groundwater depth, i.e. $-135 \mathrm{~cm}$ ) boundary conditions, show that model performance during the calibration was superior to the validation period at all observation depths (Fig. 5, Table 3). The same result was reported by Wöhling et al. (2008, 2009). Similar to the calibration period, soil water content was predicted better during the rain and irrigation period than in the dry period. Specifically, soil water content was overpredicted during summer months (June-August) and underpredicted during winter and spring. Wöhling et al. (2009) explained that the differences can be partly attributed to nonuniqueness of the optimization process, inadequacy of the model structure, the large number of optimized parameters, different information content in the calibration and evalua- 
Table 3. Calculated performance criteria describing the correspondence between measured and simulated soil water content for each scenario for various boundary conditions.

\begin{tabular}{|c|c|c|c|c|c|c|}
\hline & $\begin{array}{l}\text { Boundary } \\
\text { condition }\end{array}$ & $\begin{array}{l}\text { Number of optimized } \\
\text { parameters }\end{array}$ & $\begin{array}{l}\text { Node } \\
\text { depth }(\mathrm{cm})\end{array}$ & $\mathrm{RMSE}^{*}$ & $C_{\mathrm{e}}^{*}$ & $r^{2^{*}}$ \\
\hline \multirow{36}{*}{$\begin{array}{l}\text { Calibration } \\
\text { period } \\
(2012)\end{array}$} & \multirow{16}{*}{ Constant head $(-140 \mathrm{~cm})$} & \multirow{4}{*}{6} & 10 & 0.023 & 0.56 & 0.62 \\
\hline & & & 20 & 0.016 & 0.53 & 0.74 \\
\hline & & & 30 & 0.010 & 0.67 & 0.69 \\
\hline & & & 40 & 0.008 & 0.63 & 0.64 \\
\hline & & \multirow{4}{*}{4} & 10 & 0.024 & 0.52 & 0.62 \\
\hline & & & 20 & 0.016 & 0.54 & 0.76 \\
\hline & & & 30 & 0.010 & 0.65 & 0.70 \\
\hline & & & 40 & 0.008 & 0.64 & 0.64 \\
\hline & & \multirow{4}{*}{3} & 10 & 0.026 & 0.45 & 0.62 \\
\hline & & & 20 & 0.014 & 0.65 & 0.75 \\
\hline & & & 30 & 0.010 & 0.65 & 0.70 \\
\hline & & & 40 & 0.008 & 0.63 & 0.64 \\
\hline & & \multirow{4}{*}{2} & 10 & 0.026 & 0.46 & 0.63 \\
\hline & & & 20 & 0.014 & 0.65 & 0.75 \\
\hline & & & 30 & 0.010 & 0.66 & 0.69 \\
\hline & & & 40 & 0.010 & 0.45 & 0.63 \\
\hline & \multirow{4}{*}{ Constant head $(-120 \mathrm{~cm})$} & \multirow{4}{*}{2} & 10 & 0.022 & 0.60 & 0.61 \\
\hline & & & 20 & 0.031 & -0.65 & 0.72 \\
\hline & & & 30 & 0.025 & -0.97 & 0.64 \\
\hline & & & 40 & 0.019 & -1.01 & 0.56 \\
\hline & \multirow{12}{*}{ Free drainage } & \multirow{4}{*}{6} & 10 & 0.023 & 0.57 & 0.60 \\
\hline & & & 20 & 0.018 & 0.46 & 0.71 \\
\hline & & & 30 & 0.016 & 0.19 & 0.56 \\
\hline & & & 40 & 0.011 & 0.34 & 0.50 \\
\hline & & \multirow{4}{*}{4} & 10 & 0.022 & 0.62 & 0.64 \\
\hline & & & 20 & 0.018 & 0.45 & 0.71 \\
\hline & & & 30 & 0.014 & 0.13 & 0.55 \\
\hline & & & 40 & 0.016 & -0.11 & 0.42 \\
\hline & & \multirow{4}{*}{3} & 10 & 0.032 & 0.18 & 0.54 \\
\hline & & & 20 & 0.021 & 0.29 & 0.62 \\
\hline & & & 30 & 0.027 & 0.12 & 0.50 \\
\hline & & & 40 & 0.019 & -0.95 & 0.43 \\
\hline & & & 10 & 0.028 & 0.39 & 0.51 \\
\hline & & 2 & 20 & 0.022 & 0.31 & 0.59 \\
\hline & & 2 & 30 & 0.015 & 0.12 & 0.51 \\
\hline & & & 40 & 0.014 & -0.98 & 0.50 \\
\hline \multirow{4}{*}{$\begin{array}{l}\text { Validation } \\
\text { period } \\
(2013)\end{array}$} & \multirow{4}{*}{ Constant head $(-135 \mathrm{~cm})$} & \multirow{4}{*}{2} & 10 & 0.042 & 0.34 & 0.37 \\
\hline & & & 20 & 0.027 & 0.30 & 0.40 \\
\hline & & & 30 & 0.020 & 0.24 & 0.33 \\
\hline & & & 40 & 0.016 & 0.11 & 0.29 \\
\hline
\end{tabular}

* RMSE, $C_{\mathrm{e}}$ and $r^{2}$ are the root-mean-square deviation $\left(\mathrm{cm}^{3} \mathrm{~cm}^{-3}\right)$, the Nash-Sutcliffe coefficient of efficiency and the coefficient of determination.

tion data, and seasonal changes in soil hydraulic properties. The extent to which the soil water content prediction affects the calculated irrigation requirements is dealt with in the next section. 
Table 4. Total duration, number and extent of water stress for different boundary conditions and scenarios (from 1 March to 12 September). Total rainfall and irrigation amount were 398.2 and $64.5 \mathrm{~mm}$ in 2012 and 343.3 and $85.4 \mathrm{~mm}$ in 2013 respectively. Number between parentheses represents the duration of first water stress event due to light-radiation and temperature limitations.

\begin{tabular}{|c|c|c|c|c|c|c|c|}
\hline & $\begin{array}{l}\text { Boundary } \\
\text { condition }\end{array}$ & $\begin{array}{c}\text { Number of } \\
\text { parameters } \\
\text { optimized }\end{array}$ & $\begin{array}{c}\text { Number of } \\
\text { water stress } \\
\text { periods }\end{array}$ & $\begin{array}{l}\text { Total duration } \\
\text { of water stress }\end{array}$ & $\begin{array}{l}\text { Degree of } \\
\text { water stress }\end{array}$ & $\begin{array}{l}\text { Profile } \\
\text { bottom flux }\end{array}$ & $\begin{array}{l}\text { Yield } \\
\text { reduction }\end{array}$ \\
\hline & & & & $\mathrm{h}$ & & $\mathrm{mm}$ & $\%$ \\
\hline \multirow{5}{*}{$\begin{array}{l}\text { Calibration } \\
\text { period }\end{array}$} & Free drainage & 2 & 7 & $867(345)$ & 0.37 & -167.7 & 18 \\
\hline & Constant head $(-120 \mathrm{~cm})$ & 2 & 0 & 0 & $\geq 1$ & 71.9 & 0 \\
\hline & Constant head $(-140 \mathrm{~cm})$ & 2 & 7 & $671(328)$ & 0.65 & -15.4 & 16 \\
\hline & Constant head $(-140 \mathrm{~cm})$ & 4 & 4 & $524(277)$ & 0.65 & -1 & 13 \\
\hline & Constant head $(-140 \mathrm{~cm})$ & 6 & 5 & $540(276)$ & 0.66 & -4.6 & 13 \\
\hline \multirow{5}{*}{$\begin{array}{l}\text { Validation } \\
\text { period }\end{array}$} & Free drainage & 2 & 7 & 1093 & 0.10 & -148.7 & 23 \\
\hline & Constant head $(-120 \mathrm{~cm})$ & 2 & 1 & 20 & 0.85 & 64.4 & 0 \\
\hline & Constant head $(-135 \mathrm{~cm})$ & 2 & 5 & 675 & 0.65 & 63.3 & 13 \\
\hline & Constant head $(-135 \mathrm{~cm})$ & 4 & 4 & 598 & 0.65 & 76.6 & 11 \\
\hline & Constant head $(-135 \mathrm{~cm})$ & 6 & 3 & 579 & 0.65 & 76.9 & 11 \\
\hline
\end{tabular}

\subsection{Effect of optimization scenarios on estimated water stress and yield reduction}

Using the two-parameter optimization scenario (Table 4), the calculated potential-reference evapotranspiration $\left(\mathrm{ET}_{\mathrm{o}}\right)$ values for 2012 and 2013 (same period from 1 March to 12 September) were 523 and $524 \mathrm{~mm}$, respectively. The cumulative actual transpiration and evaporation, provided by the hydrological model, were 353 and $86 \mathrm{~mm}$ for the calibration (2012) and 343 and $114 \mathrm{~mm}$ for validation (2013) periods. Calculated cumulative actual fluxes across the bottom of the soil profile were $-15.4 \mathrm{~mm}$ (outflow) and $63.3 \mathrm{~mm}$ (upward inflow), respectively. The calculations are valid for the location where the soil moisture sensor was placed, i.e. in the drier part of the field with groundwater depths below $120 \mathrm{~cm}$. The sum of irrigation and precipitation over the simulation period was $463 \mathrm{~mm}$ (64.5 mm irrigation and $398.5 \mathrm{~mm}$ precipitation) in 2012 and $428.7 \mathrm{~mm}$ (85.4 mm irrigation and $343.3 \mathrm{~mm}$ precipitation) in 2013. In 2013, the amount of water from irrigation and rainfall was lower as compared to 2012, resulting in a larger recharge from the groundwater. Overall, the periods of water stress totalled $671 \mathrm{~h}$ in 2012 and $675 \mathrm{~h}$ in 2013 (Table 4). Despite the similarity, the extent of soil water stress was larger in 2013 as compared to 2012. This can be attributed to the fact that the first water stress event in 2012 with about $328 \mathrm{~h}$ duration is not related to soil water availability but is also due to climate limitations (low temperature and light-radiation limitation). No significant reduction or increase in yield and LAI was achieved during this first water stress event in current and optimum conditions (Fig. 3).

There was a significant effect of the bottom boundary condition on the calculated water stress. A free drainage condition resulted in a larger number, longer duration of stress con- ditions (Fig. 6 and Table 4) and overestimated water stress due to excessive recharge to the groundwater (more than $148 \mathrm{~mm}$ ). On the other hand, a shallower imposed groundwater level $(-120 \mathrm{~cm})$ creates less estimated water stress (Fig. 6 and Table 4), because this boundary condition allows inflow (upward flow) from the groundwater table. When the groundwater level was $-140 \mathrm{~cm}$ the outflow of the bottom flux increased from the six-optimized parameter scenario $(-4.6 \mathrm{~mm})$ to the two-parameter scenario $(-15.4 \mathrm{~mm})$ in the calibration period, while upward flow increased with increasing number of optimized parameters in validation period $(63.3$ to $76.9 \mathrm{~mm})$. But these inflows did not meet the crop water requirement (see next section). Huo et al. (2012) reported that the maximum contribution of groundwater level to crop water requirement occurred when the groundwater level was less than $100 \mathrm{~cm}$. Overall, to overcome the water stress effects on crop yield, additional irrigation should be supplied for different optimization scenarios and boundary conditions. During water stress, yield reduction would be in range of 0 to $33 \%$ for different optimization scenarios (Table 4). In addition, two- to six-parameter optimizations showed a similar value in yield reduction ( $16 \%$ for two- and $13 \%$ for three- to six-parameter in calibration; and $13 \%$ for two- and $11 \%$ for three- to six-parameters to be optimized in validation periods). The maximum yield reduction occurred in the free drainage condition among different boundary conditions and parameter optimization scenarios. Different parameter optimization strategies (two-, three-, fouror six-parameter optimizations) do not affect the calculated water stress as significantly as does the bottom boundary. Therefore, these results suggest that simultaneous optimization is needed for irrigation management purposes, i.e. optimize/choosing boundary conditions to accurately describe recharge to or from groundwater and, in second order, opti- 

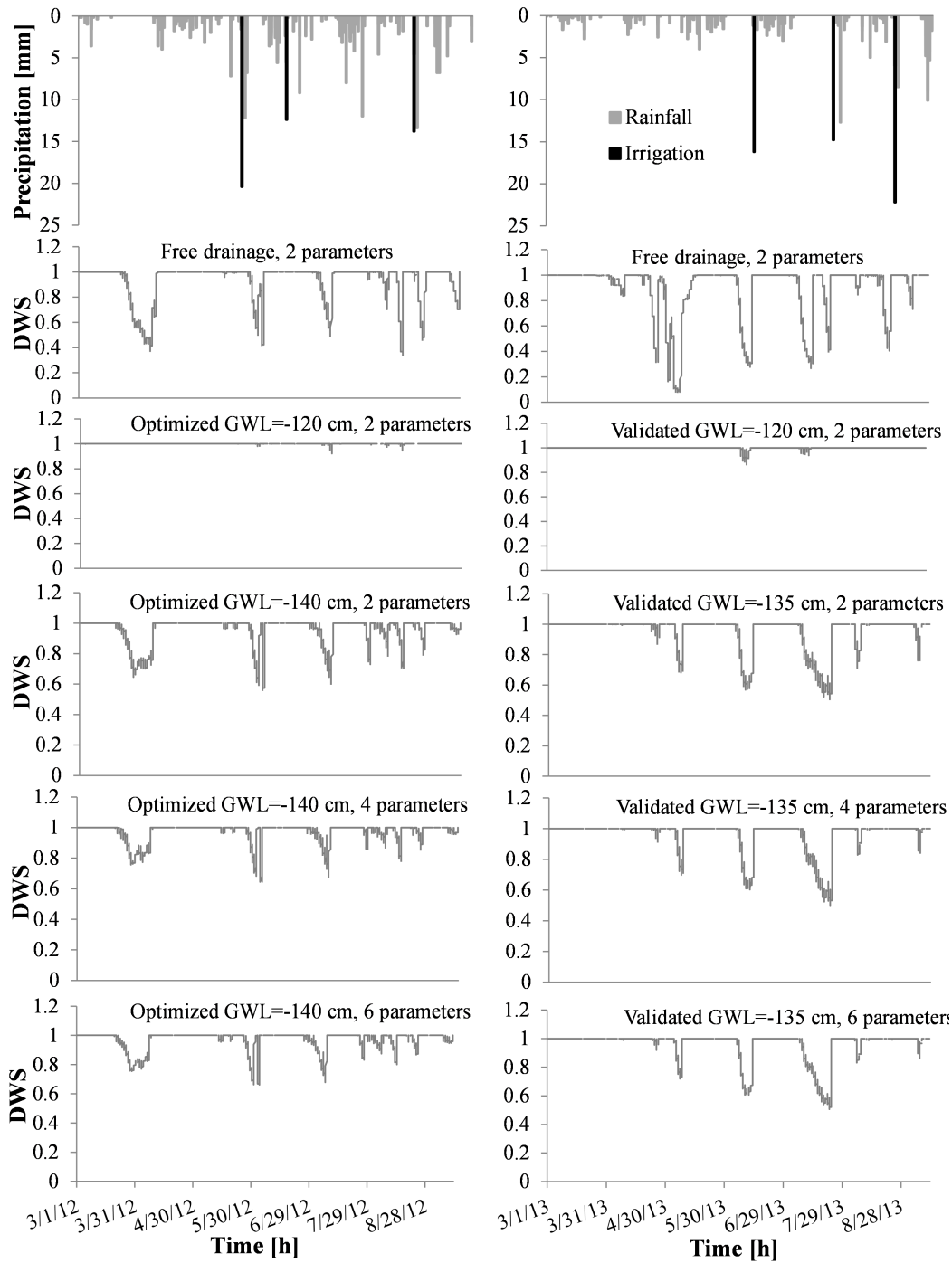

Figure 6. Degree of water stress at potential reference evapotranspiration in 2012 and 2013 for various scenarios and bottom boundary conditions.

Table 5. Comparison of optimized irrigation schedule with farmer's conventional irrigation schedule.

\begin{tabular}{|c|c|c|c|c|c|c|c|c|}
\hline \multirow{2}{*}{ Boundary condition } & \multicolumn{3}{|c|}{ Observed irrigation schedule } & \multirow[b]{2}{*}{ Yield simulated } & \multicolumn{3}{|c|}{ Optimized irrigation schedule } & \multirow{2}{*}{$\begin{array}{l}\text { Difference } \\
\begin{array}{l}\text { amount } \\
(\mathrm{mm})\end{array}\end{array}$} \\
\hline & $\begin{array}{l}\text { Time } \\
\text { (day) }\end{array}$ & $\begin{array}{l}\text { amount } \\
(\mathrm{mm})\end{array}$ & $\begin{array}{l}\text { Yield observed } \\
\left(\mathrm{tha}^{-1}\right)\end{array}$ & & $\begin{array}{l}\text { Time } \\
\text { (day) }\end{array}$ & $\begin{array}{l}\text { amount } \\
(\mathrm{mm})\end{array}$ & $\begin{array}{l}\text { Yield simulated } \\
\left(\mathrm{tha}^{-1}\right)\end{array}$ & \\
\hline Calibration period (2012) & 20 May & 22.5 & & & 27 May & 15 & & \\
\hline Constant head $(-140 \mathrm{~cm})$ with & 11 June & 21 & 10.39 & 10.91 & 2 July & 15 & 11.39 & 14.5 \\
\hline 2 optimized parameters & 13 August & 21 & & & 11 August & 20 & & \\
\hline Validation period (2013) & 13 June & 32.4 & & & 6 June & 25 & & \\
\hline Constant head $(-135 \mathrm{~cm})$ with & 23 July & 24.8 & 10.83 & 11.11 & 8 July & 25 & 11.82 & 10.4 \\
\hline 2 optimized parameters & 23 August & 28.2 & & & 17 July & 25 & & \\
\hline
\end{tabular}

mize hydraulic parameters to accurately describe soil water content variation in the topsoil.

\subsection{Irrigation scheduling scheme}

The simulated results further showed that, to avoid drought stress during summer, a more accurate irrigation schedule 

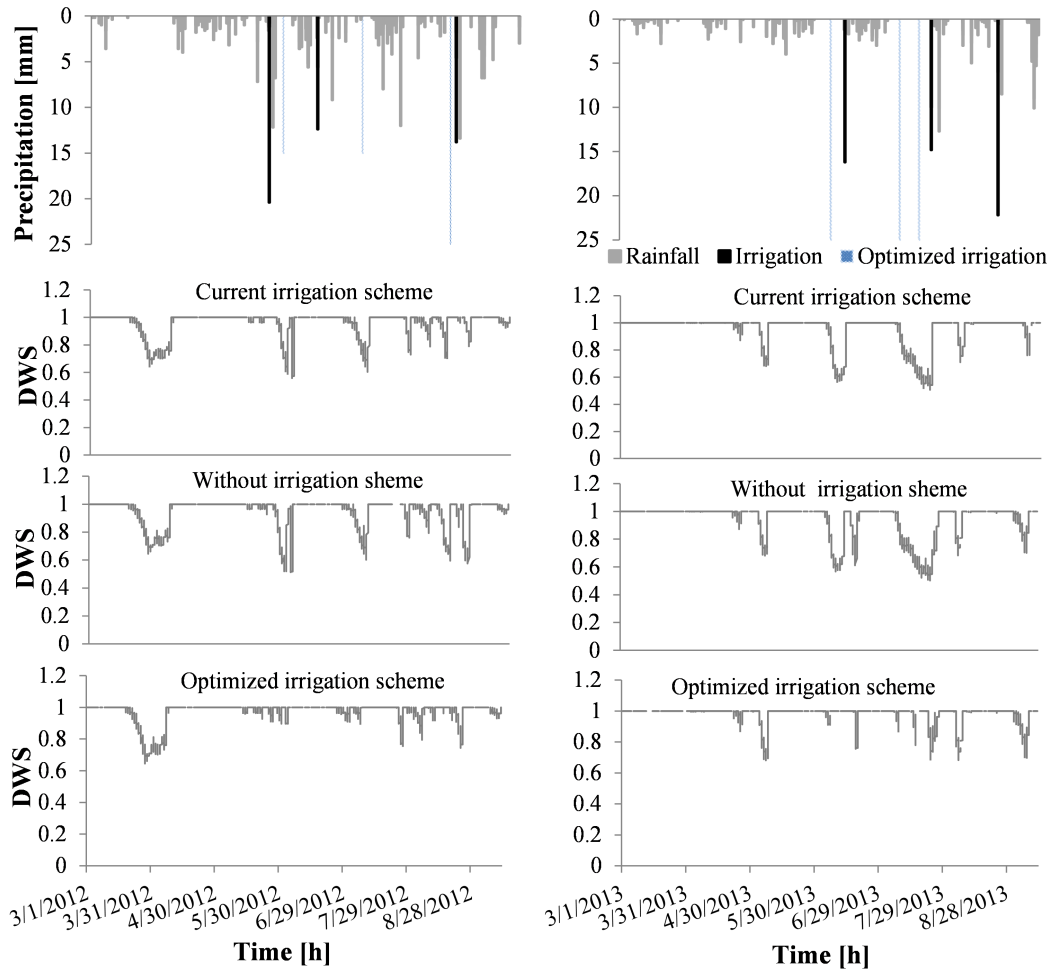

Figure 7. Comparison degree of water stress between farmer's conventional irrigation (current irrigation), without irrigation and optimized irrigation scheme for calibration and validation periods.

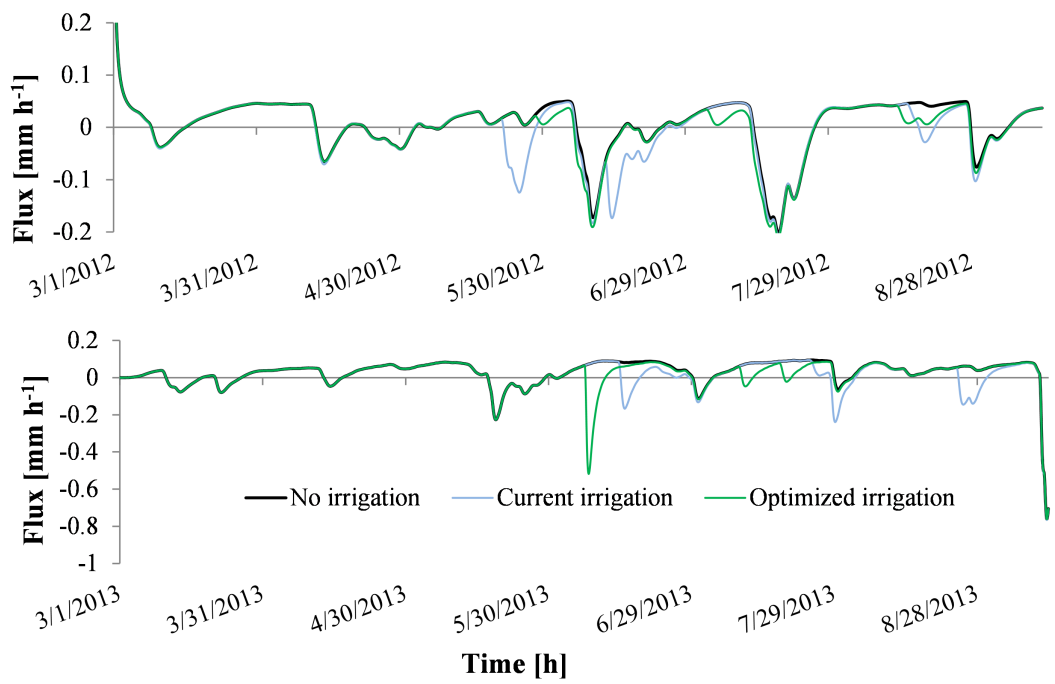

Figure 8. Actual flux of farmer's conventional irrigation (current irrigation), without irrigation and optimized irrigation scheme (guided irrigation) for 2012 and 2013.

would be needed in the drier part of the field. It would be better to supply water in June and July instead of a huge amount in late summer or at an inappropriate time (see Figs. 6 and 7). Results revealed that the actual water supply exceeded crop demand but did not meet the crop requirement (Fig. 7 and Table 5). Irrigation volume affects soil water fluxes. In the "no irrigation" scenario for 2012 the upward/inflow fluxes from groundwater were larger than current and guided irrigation scenarios (Fig. 8). The upward flow of water was not sufficient to meet the crop requirement. For guided irrigation, recharge from groundwater was larger than current irrigation in 2012 and 2013 - which means some part of crop water de- 
mand would need to be supplied from groundwater in guided irrigation.

Results show that, despite reducing water supply throughout the growth period by about $22.5 \%$ in 2012 and $12 \%$ in 2013, yield would have increased about $4.5 \%$ in 2012 and $6.5 \%$ in 2013 on average (Table 5, Fig. 3), by rescheduling irrigation at the precise time when the crop is exposed to water stress. The number of irrigation events would remain similar to realistic applications (three times in each growing season). At the field scale, non-uniform irrigation distribution (water supply in drier parts with groundwater level below $120 \mathrm{~cm}$ ) would be necessary.

\section{Conclusions}

The results of this study have demonstrated clearly the profound effect of the position of the groundwater table on the estimated soil water content and associated water stress in a sandy two-layered soil under grass in a temperate maritime climate. Indeed, field-scale variations in soil water content can be very large, due to topography and variable depth of the groundwater. Furthermore, the model performance was affected by the spatial variability of hydraulic parameters such as $K_{\mathrm{S}}$. Results show that the uniform distribution of water using standard gun sprinkler irrigation may not be an efficient approach since at locations with shallow groundwater, the amount of water applied will be excessive as compared to the crop requirements, while in locations with a deeper groundwater table, the crop irrigation requirements will not be met during crop water stress.

The results show that the effect of groundwater level was dominant in soil water content prediction, at least under conditions similar to those in our study. This reflects the need for accurate determination of the bottom boundary condition, both in space and time. In a subsequent field experiment in an adjacent field, the temporal fluctuations of the groundwater table based on diver (Mini-Diver, Eijkelkamp Agrisearch Equipment, Giesbeek, the Netherlands) measurements in boreholes revealed changes in groundwater depth of about $10 \mathrm{~cm}$. The temporal changes were smaller than the expected variation due to topography which may well range more than $100 \mathrm{~cm}$ even for relatively flat areas. This has important consequences for precision irrigation management and variable water applications at sub-field scale. The use of detailed (cm scale) digital elevation models, geophysical measurement techniques such as electromagnetic induction or ground-penetrating radar as proxies for hydraulic parameters will serve as valuable data sources for hydrological models to calculate variable irrigation requirements within agricultural fields. The parametrization scenarios in the calibration and validation stage of model development should be kept simple in view of the information they generate. We have shown that it is sufficient to estimate a limited amount of key parameters for which the temporal variant informa- tion of the sensitivity is crucial, and also that optimization strategies involving multiple parameters do not perform better in view of the optimization of irrigation management. We have shown that a combined modelling approach could increase water use efficiency (12-22.5\%) and yield (5-7\%) by changing the irrigation scheduling. However, these efficiencies can only be achieved if rainfall is known a priori- while the soil water status could indicate when to irrigate, it would be impossible to know how much to irrigate if the rainfall cannot be accurately predicted. Therefore, the results of the study call for taking into account accurate weather forecast and water content data in irrigation management and precision agriculture. The combination of accurate and spatially distributed field data with appropriate numerical models will make it possible to accurately determine the field-scale irrigation requirements, taking into account variations in boundary conditions across the field and the spatial variations of model parameters. The information gained in this study with respect to dominant parameters and the effect of boundary conditions at the plot scale (1-D) will be scaled up in a 2-D approach to the field scale using detailed spatial information on groundwater depth and hydraulic conductivity $K_{\mathrm{s}}$.

\section{The Supplement related to this article is available online at doi:10.5194/hess-20-487-2016-supplement.}

Acknowledgements. This work was funded by the Ministry of Science, Research and Technology (MSRT) of Iran, Ghent University and Flemish Institute for Technological Research (VITO) of Belgium. The authors are grateful to all study participants for their contributions, especially the farmer and field owner Jacob Van Den Borne and Ghent University laboratory staff for the great technical support.

Edited by: N. Romano

\section{References}

Abbasi, F., Jacques, D., Simunek, J., Feyen, J., and van Genuchten, M. T.: Inverse estimation of soil hydraulic and solute transport parameters from transient field experiments: Heterogeneous soil, T. ASAE, 46, 1097-1111, 2003.

Abbasi, F., Feyen, J., and van Genuchten, M. T.: Two-dimensional simulation of water flow and solute transport below furrows: model calibration and validation, J. Hydrol., 290, 63-79, doi:10.1016/j.jhydrol2.003.11.028, 2004.

Akhtar, F., Tischbein, B., and Awan, U. K.: Optimizing deficit irrigation scheduling under shallow groundwater conditions in lower reaches of Amu Darya river basin, Water Resour. Manag., 27, 3165-3178, doi:10.1007/s11269-013-0341-0, 2013.

Allen, R. G., Pereira, L. S., Raes, D., and Smith, M.: Crop evapotranspiration, FAO Irrig. Drain. Pap. 56, Rome, Italy, 174 pp., 1998. 
American Society of Civil Engineers (ASCE): Criteria for Evaluation of Watershed Models, Journal of Irrigation and Drainage Engineering, 119, 429-442, doi:10.1061/(ASCE)07339437(1993)119:3(429), 1993.

Awan, U., Tischbein, B., Kamalov, P., Martius, C., and Hafeez, M.: Modeling Irrigation Scheduling Under Shallow Groundwater Conditions as a Tool for an Integrated Management of Surface and Groundwater Resources, in: Cotton, Water, Salts and Soums, edited by: Martius, C., Rudenko, I., Lamers, J. P. A., and Vlek, P. L. G., Springer Netherlands, 309-327, 2012.

Barrett, P. D., Laidlaw, A. S., and Mayne, C. S.: An evaluation of selected perennial ryegrass growth models for development and integration into a pasture management decision support system, J. Agr. Sci., 142, 327-334, doi:10.1017/S0021859604004289, 2004.

Brun, R., Reichert, P., and Kunsch, H. R.: Practical identifiability analysis of large environmental simulation models, Water Resour. Res., 37, 1015-1030, doi:10.1029/2000wr900350, 2001.

Brutsaert, W.: Hydrology, An Introduction, Cambrige University Press, Cambridge, UK, 618 pp., 2005.

Caldwell, T. G., Wöhling, T., Young, M. H., Boyle, D. P., and McDonald, E. V.: Characterizing Disturbed Desert Soils Using Multiobjective Parameter Optimization, Vadose Zone J., 12, 1-23, doi:10.2136/vzj2012.0083, 2013.

Cornelis, W. M., Khlosi, M., Hartmann, R., Van Meirvenne, M., and De Vos, B.: Comparison of unimodal analytical expressions for the soil-water retention curve, Soil Sci. Soc. Am. J., 69, 19021911, doi:10.2136/sssaj2004.0238, 2005.

Doorenbos, J. and Kassam, A. H.: Yield response to water, FAO Irrigation and Drainage Paper No. 33, Rome, Italy, 1979.

Evett, S. R., Heng, L. K., Moutonnet, P., and Nguyen, M. L.: Field estimation of soil water content: A practical guide to methods, instrumentation and sensor technology, IAEA-TCS-30, Vienna, Austria, 2008.

FAO: World reference base for soil resources: keys to reference soil groups of the world, Rome, report no. 84. 96 pp., 1998.

FAO: Climate change, water and food security, edited by: Turra, H., Burke, J., and Faurès, J. M., in: Food and agrriculture organization of the united nation Rome, Italy, 174 pp., 2011.

Feddes, R. A., Kowalik, P. J., and Zaradny, H.: Simulation of field water use and crop yield., Simul. Monogr. Pudoc, Wageningen, The Netherlands, 189 pp., 1978.

Fernández-Gálvez, J., Simmonds, L. P., and Barahona, E.: Estimating detailed soil water profile records from point measurements, Eur. J. Soil Sci., 57, 708-718, doi:10.1111/j.13652389.2005.00761.x, 2006.

Gandolfi, C., Facchi, A., and Maggi, D.: Comparison of 1D models of water flow in unsaturated soils, Environ. Modell. Softw., 21, 1759-1764, doi:10.1016/j.envsoft.2006.04.004, 2006.

Gee, G. W. and Bauder, J. W.: Particle-size analysis, in: Methods of soil analysis, Part 1, 2nd edn, 2nd ed., edited by: Klute, A., Soil Science Society of America, Madison, 383-411, 1986.

Hall, J. M.: How well does your model fit the data?, J. Hydroinform., 3, 49-55, 2001.

Hopmans, J. W., Šimůnek, J., Romano, N., and Durner, W.: Simultaneous determination of water transmission and retention properties. Inverse Methods, in: Method of soil analysis. Part 4. Physical methods, edited by: Dane, J. H. and Topp, G. C., Soil Sci- ence Society of America Book Series, Madison, USA, 963-1008, 2002.

Huo, Z., Feng, S., Dai, X., Zheng, Y., and Wang, Y.: Simulation of hydrology following various volumes of irrigation to soil with different depths to the water table, Soil Use Manage., 28, 229239, doi:10.1111/j.1475-2743.2012.00393.x, 2012.

Jacques, D., Smith, C., Simunek, J., and Smiles, D.: Inverse optimization of hydraulic, solute transport, and cation exchange parameters using HP1 and UCODE to simulate cation exchange, J. Contam. Hydrol., 142, 109-125, doi:10.1016/j.jconhyd.2012.03.008, 2012.

Jarvis, N. J.: A simple empirical model of root water uptake, J. Hydrol., 107, 57-72, doi:10.1016/0022-1694(89)90050-4, 1989.

Jones, H. G.: Irrigation scheduling: advantages and pitfalls of plant-based methods, J. Exp. Bot., 55, 2427-2436, doi:10.1093/jxb/erh213, 2004.

Kelleners, T. J., Soppe, R. W. O., Ayars, J. E., Simunek, J., and Skaggs, T. H.: Inverse analysis of upward water flow in a groundwater table lysimeter, Vadose Zone J., 4, 558-572, doi:10.2136/Vzj2004.0118, 2005.

Krause, P., Boyle, D. P., and Bäse, F.: Comparison of different efficiency criteria for hydrological model assessment, Adv. Geosci., 5, 89-97, doi:10.5194/adgeo-5-89-2005, 2005.

Li, Y., Kinzelbach, W., Zhou, J., Cheng, G. D., and Li, X.: Modelling irrigated maize with a combination of coupled-model simulation and uncertainty analysis, in the northwest of China, Hydrol. Earth Syst. Sci., 16, 1465-1480, doi:10.5194/hess-16-14652012, 2012.

Mertens, J., Stenger, R., and Barkle, G. F.: Multiobjective inverse modeling for soil parameter estimation and model verification, Vadose Zone J., 5, 917-933, doi:10.2136/Vzj2005.0117, 2006.

Mohanty, B. P., Cosh, M., Lakshmi, V., and Montzka, C.: Remote sensing for vadose zone hydrology: A synthesis from the vantage point, Vadose Zone J., 12, 1-6, doi:10.2136/vzj2013.07.0128, 2013.

Mualem, Y.: New model for predicting hydraulic conductivity of unsaturated porous-media, Water Resour. Res., 12, 513-522, doi:10.1029/Wr012i003p00513, 1976.

Nasta, P., Vrugt, J. A., and Romano, N.: Prediction of the saturated hydraulic conductivity from Brooks and Corey's water retention parameters, Water Resour. Res., 49, 2918-2925, 2013.

Neuman, S. P. and Wierenga, P. J.: A comprehensive strategy of hydrogeologic modeling and uncertainty analysis for nuclear facilities and sites, Division of Systems Analysis and Regulatory Effectiveness, Office of Nuclear Regulatory Research, US Nuclear Regulatory Commission, Washington, DC, 2003.

Nosetto, M. D., Jobbagy, E. G., Brizuela, A. B., and Jackson, R. B.: The hydrologic consequences of land cover change in central Argentina, Agr. Ecosyst. Environ., 154, 2-11, doi:10.1016/j.agee.2011.01.008, 2012.

Pardossi, A., Incrocci, L., Incrocci, G., Malorgio, F., Battista, P., Bacci, L., Rapi, B., Marzialetti, P., Hemming, J., and Balendonck, J.: Root zone sensors for irrigation management in intensive agriculture, Sensors-Basel, 9, 2809-2835, doi:10.3390/S90402809, 2009.

Rezaei, M., Saey, T., Seuntjens, P., Joris, I., Boënne, W., Van Meirvenne, M., and Cornelis, W.: Predicting saturated hydraulic conductivity in a sandy grassland using proximally sensed apparent electrical conductivity, J. Appl. Geophys., 126, 35-41, 2016. 
Richards, L. A.: Capillary conduction of liqids through porous mediums, J. Appl. Phys., 1, 318-333, doi:10.1063/1.1745010, 1931.

Ritter, A., Hupet, F., Muñoz-Carpena, R., Lambot, S., and Vanclooster, M.: Using inverse methods for estimating soil hydraulic properties from field data as an alternative to direct methods, Agr. Water Manage., 59, 77-96, doi:10.1016/S0378-3774(02)001609, 2003.

Rocha, D., Abbasi, F., and Feyen, J.: Sensitivity analysis of soil hydraulic properties on subsurface water flow in furrows, J. Irrig. Drain E-ASCE, 132, 418-424, doi:10.1061/(Asce)07339437(2006)132:4(418), 2006.

Sadeghi, M. and Jones, S. B.: Scaled solutions to coupled soil-water flow and solute transport during the redistribution process, Vadose Zone J, 11, 10 pp., doi:10.2136/Vzj2012.0023, 2012.

Saltelli, A., Ratto, M., Andres, T., Campolongo, F., Cariboni, J., Gatelli, D., Saisana, M., and Tarantola, S.: Global sensitivity analysis, The Primer, John Wiley \& Sons, West Sussex, England, 296 pp., 2008.

Satchithanantham, S., Krahn, V., Sri Ranjan, R., and Sager, S.: Shallow groundwater uptake and irrigation water redistribution within the potato root zone, Agr. Water Manage., 132, 101-110, 2014.

Schapendonk, A. H. C. M., Stol, W., van Kraalingen, D. W. G., and Bouman, B. A. M.: LINGRA, a sink/sourced model to simulate grassland productivity in Europe, Eur. J. Agr., 9, 87-100, 1998.

Schneider, S., Jacques, D., and Mallants, D.: Inverse modelling with a genetic algorithm to derive hydraulic properties of a multilayered forest soil, Soil Res., 51, 372-389, doi:10.1071/Sr13144, 2013.

Schwartz, R. C. and Evett, S. R.: Estimating hydraulic properties of a fine-textured soil using a disc infiltrometer, Soil Sci. Soc. Am. J., 66, 1409-1423, 2002.

Šimůnek, J. and Hopmans, J. W.: Parameter optimization and nonlinear fitting, in: Method of soil analysis. Part 4. Physical methods, edited by: Dane, J. H. and Topp, G. C., Soil Science Society of America Book Series, 139-157, 2002.

Šimůnek, J., Šejna, M., Saito, H., Sakai, M., and van Genuchten, M. T.: The Hydrus-1D software package for simulating the movement of water, heat, and multiple solutes in variably saturated media, version 4.16, HYDRUS software series 3 Department of Environmental Sciences, University of California Riverside, Riverside, California, USA, 308 pp., 2013.

Skaggs, T. H., Shouse, P. J., and Poss, J. A.: Irrigating forage crops with saline waters: 2 . Modeling root uptake and drainage, Vadose Zone J., 5, 824-837, doi:10.2136/Vzj2005.0120, 2006.

Tafteh, A. and Sepaskhah, A. R.: Application of HYDRUS-1D model for simulating water and nitrate leaching from continuous and alternate furrow irrigated rapeseed and maize fields, Agr. Water Manage., 113, 19-29, doi:10.1016/j.agwat.2012.06.011, 2012.

Taylor, S. T. and Ashcroft, G. L.: Physical edaphology: The physics of irrigated and nonirrigated soils, W. H. Freeman, San Francisco, CA, 533 pp., 1972.

van Dam, J. C., Groenendijk, P., Hendriks, R. F. A., and Kroes, J. G.: Advances of Modeling Water Flow in Variably Saturated Soils with SWAP Vadose Zone J., 7, 640-653, doi:10.2136/vzj2007.0060, 2008. van Genuchten, M. T.: A closed-form equation for predicting the hydraulic conductivity of unsaturated soils, Soil Sci. Soc. Am. J., 44, 892-898, 1980.

van Genuchten, M. T., Leij, F. J., and Yates, S. R.: The RETC code for quantifying the hydraulic functions of unsaturated soils, version 1.0, USDA, ARS, Riverside, CA, 85 pp., 1991.

van Genuchten, M. T., Simunek, J., Leij, F. J., Toride, N., and Sejna, M.: Stanmod: Model use, calibration, and validation, T. ASABE, 55, 1353-1366, 2012.

Verbist, K., Baetens, J., Cornelis, W. M., Gabriels, D., Torres, C., and Soto, G.: Hydraulic Conductivity as Influenced by Stoniness in Degraded Drylands of Chile, Soil Sci. Soc. Am. J., 73, 471484, doi:10.2136/sssaj2008.0066, 2009.

Verbist, K. M. J., Pierreux, S., Cornelis, W. M., McLaren, R., and Gabriels, D.: Parameterizing a coupled surface-subsurface threedimensional soil hydrological model to evaluate the efficiency of a runoff water harvesting technique, Vadose Zone J., 11, 17 pp., doi:10.2136/Vzj2011.0141, 2012.

Vrugt, J. A., van Wijk, M. T., Hopmans, J. W., and Simunek, J.: One-, two-, and three-dimensional root water uptake functions for transient modeling, Water Resour. Res., 37, 2457-2470, doi:10.1029/2000wr000027, 2001.

Vrugt, J. A., Schoups, G., Hopmans, J. W., Young, C., Wallender, W. W., Harter, T., and Bouten, W.: Inverse modeling of large-scale spatially distributed vadose zone properties using global optimization, Water Resour. Res., 40, W06503, doi:10.1029/2003wr002706, 2004.

Walkley, A. and Black, I. A.: An examination of the Degtjareff method for determining soil organic matter, and a proposed modification of the chromic acid titration method, Soil Science 37, 29-38, 1934.

Wegehenkel, M. and Beyrich, F.: Modelling hourly evapotranspiration and soil water content at the grass-covered boundary-layer field site Falkenberg, Germany, Hydrol. Sci. J., 59, 376-394, doi:10.1080/02626667.2013.835488, 2014.

Wöhling, T. and Vrugt, J. A.: Multiresponse multilayer vadose zone model calibration using Markov chain Monte Carlo simulation and field water retention data, Water Resour. Res., 47, 19 pp., doi:10.1029/2010wr009265, 2011.

Wöhling, T., Vrugt, J. A., and Barkle, G. F.: Comparison of three multiobjective optimization algorithms for inverse modeling of vadose zone hydraulic properties, Soil Sci. Soc. Am. J., 72, 305 319, doi:10.2136/sssaj2007.0176, 2008.

Wöhling, T., Schütze, N., Heinrich, B., Šimůnek, J., and Barkle, G. F.: Three-dimensional modeling of multiple automated equilibrium tension lysimeters to measure vadose zone fluxes, Vadose Zone J., 8, 1051-1063, doi:10.2136/vzj2009.0040, 2009.

Wolf, J.: LINGRA-N a grassland model for potential, water limited and $\mathrm{N}$ limited conditions (FORTRAN), Wageningen University, Wageningen, The Netherlands, 65 pp., 2012.

Wollschlager, U., Pfaff, T., and Roth, K.: Field-scale apparent hydraulic parameterisation obtained from TDR time series and inverse modelling, Hydrol. Earth Syst. Sci., 13, 1953-1966, 2009.

Zhou, J., Cheng, G. D., Li, X., Hu, B. X., and Wang, G. X.: Numerical Modeling of Wheat Irrigation using Coupled HYDRUS and WOFOST Models, Soil Sci. Soc. Am. J., 76, 648-662, doi:10.2136/sssaj2010.0467, 2012. 